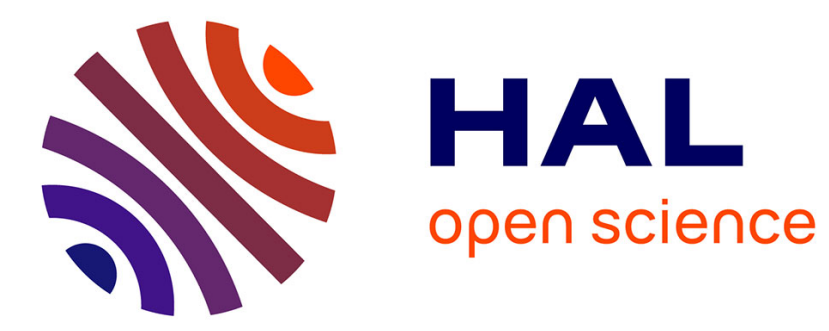

\title{
A sorting method to value recycled concrete
}

Régis Sebben Paranhos, Bogdan Cazacliu, Carlos Hoffmann Sampaio, Carlos

Petter, Raul Oliveira Neto, Florian Huchet

\section{To cite this version:}

Régis Sebben Paranhos, Bogdan Cazacliu, Carlos Hoffmann Sampaio, Carlos Petter, Raul Oliveira Neto, et al.. A sorting method to value recycled concrete. Journal of Cleaner Production, 2016, 112 (4), pp.2249-2258. 10.1016/j.jclepro.2015.10.021 . hal-01533197

\section{HAL Id: hal-01533197 \\ https://hal.science/hal-01533197}

Submitted on 6 Jun 2017

HAL is a multi-disciplinary open access archive for the deposit and dissemination of scientific research documents, whether they are published or not. The documents may come from teaching and research institutions in France or abroad, or from public or private research centers.
L'archive ouverte pluridisciplinaire HAL, est destinée au dépôt et à la diffusion de documents scientifiques de niveau recherche, publiés ou non, émanant des établissements d'enseignement et de recherche français ou étrangers, des laboratoires publics ou privés. 


\section{Accepted Manuscript}

A sorting method to value recycled concrete

Régis Sebben Paranhos, Bogdan Grigore Cazacliu, Carlos Hoffmann Sampaio, Carlos Otávio Petter, Raul Oliveira Neto, Florian Huchet

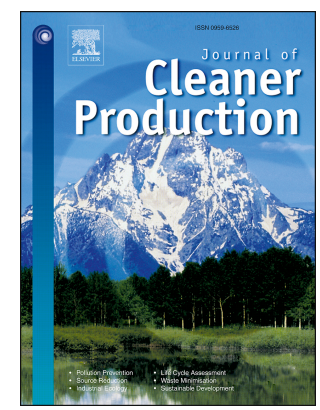

PII:

S0959-6526(15)01405-5

DOI:

10.1016/j.jclepro.2015.10.021

Reference: JCLP 6252

To appear in: Journal of Cleaner Production

Received Date: 19 November 2014

Revised Date: 5 October 2015

Accepted Date: 6 October 2015

Please cite this article as: Paranhos RS, Cazacliu BG, Sampaio CH, Petter CO, Neto RO, Huchet F, A sorting method to value recycled concrete, Journal of Cleaner Production (2015), doi: 10.1016/ j.jclepro.2015.10.021.

This is a PDF file of an unedited manuscript that has been accepted for publication. As a service to our customers we are providing this early version of the manuscript. The manuscript will undergo copyediting, typesetting, and review of the resulting proof before it is published in its final form. Please note that during the production process errors may be discovered which could affect the content, and all legal disclaimers that apply to the journal pertain. 


\title{
A sorting method to value recycled concrete
}

\author{
Régis Sebben Paranhos ${ }^{1}$, Bogdan Grigore Cazacliu ${ }^{2}$, Carlos Hoffmann Sampaio ${ }^{3}$, Carlos \\ Otávio Petter ${ }^{3}$, Raul Oliveira Neto ${ }^{1}$, Florian Huchet ${ }^{2}$ \\ ${ }^{1}$ Federal University of Pampa (UNIPAMPA). Mining, Planning and Mineral Processing Laboratory (LATRAM), \\ Av. Pedro Anunciação, 111, Caçapava do Sul, Brazil. \\ ${ }^{2}$ LUNAM, University of Nantes, IFSTTAR, Aggregates and Material Processing Laboratory, Route de Bouaye - \\ CS4, 44344 Cedex Bouguenais, Nantes, France. \\ ${ }^{3}$ Federal University of Rio Grande do Sul (UFRGS), Engineering School, Department of Metallurgy, Av. Bento \\ Gonçalves, 9500, Agronomia, 91501-970, Porto Alegre, Brazil.
}

Corresponding Author: E-mail: regis.paranhos@unipampa.edu.br. Tel.: +55-51-93736488

\section{Highlights}

A new method to valorise recycled concrete aggregates with high quality.

Gravity concentration and sensor-based sorting to treat construction and demolition waste.

Mineral processing techniques applied to recycled and demolition waste.

\begin{abstract}
The purpose of this paper is to propose a sorting platform to increase the quality of recycled aggregates through the supplementary use of mineral processing techniques and additional sorting. The difficulty of liberation is discussed, and the methodology currently used in mineral processing is proposed. Jigs, hydrocyclones and sensor-based sorting are considered to have good performance in the sorting of adequately recycled aggregates.

The new perspectives on sorting and liberation for recycling aggregates are discussed. The new process is presented based on the current process in recycling platforms, with supplementary sorting of the recycled concrete. The gain in density and the reduction in water absorption are studied. The relation between the water content and the density of aggregates is analysed for three quality levels of recycled aggregates.

The gain in density and the reduction in water absorption were linked to the aggregate replacement rates. The reduction in transport and discharge costs due to the increased aggregate quality was linked to the aggregate replacement rate and distance to quarry. In our study, replacing a lower-quality aggregate with another of medium quality leads to an expected density gain of approximately $4 \%$. Conversely, if replaced by superior quality aggregate, the expected gain will be $8.4 \%$. As a consequence, a $34 \%$ reduction in water absorption could also be obtained.

The cost reduction is exponential with the substitution rate of recycled materials. There is a decrease in transport costs if the quality of recycled aggregates increases. Conversely, if the reduction in transport costs when the quality of recycled aggregates increases is considered, the distance between the demolition site and quarry is not important.
\end{abstract}

Keywords: recycling platform, recycled concrete, sorting methodology 


\section{Introduction}

The construction industry is a major solid waste generator worldwide (Ulsen, 2013). Construction and Demolition Waste (CDW) is generated through the construction, renovation, and demolition processes for residential or commercial buildings, roads, bridges, etc. The CDW material usually is not (re)used and becomes an important environmental problem (Raoa et al., 2007). CDW material can be stocked in landfills, and the inert part is traditionally disposed of in roads, dams, etc.

The reuse of a portion of these inert wastes from construction materials has been extensively studied, especially the reuse of Recycled Concrete Aggregate (RCA) in new concrete mix design. Muigai (2013) has studied the RCA in a life-cycle study of concrete structures. The main hindrance to the use of recycled aggregates for structural applications is the high investment cost in recycling. Additionally, there is a lack of regulatory requirements on concrete recycling. Mulder (2006) described the closed cycle construction concept. In this case, the processed materials can be reused at their original quality level and the quantity of waste to be disposed is minimised. This means that after demolition, concrete, masonry and mixed stony rubble are separated and treated individually. However, these treatments often use thermal processes. Tam (2006) described the closed cycle construction as having a higher environmental value than recycling. Landfilling and incineration have high environmental impacts, while recycling and reuse are considered to have low environmental impacts. In this vision, according to Tam (2006), many strategies are possible, as is it necessary to implement innovative demolition methods: setting up the recycling plant close to the site; setting up mobile installations; providing greater flexibility in receiving concrete waste at the recycling plant; and establishing laws and incentives for recycling development. According to Shepper (2014), the environmental impact of the concrete mixtures regarding the other impact categories is mainly related to their cement and fly ash content and the required transportation.

To facilitate recycling, automatic optical sorting was developed in the mining industry to process different ores. Gülsoy et al. (2012) studied optical sorting with CCD cameras in coal beneficiation. The technique was used to improve coal beneficiation for coals with high proportions of near-gravity materials. Optical sorting was tested with positive results for materials having significant colour differences. Ergün et al. (2012) used optical sorting to treat iron and chromium ores. For iron ores, samples were taken from a magnetite processing plant. The purpose of the study was to concentrate hematite that was mixed with silicates. Optical sorting depends of many factors, such as particle size, surface conditions, light source, and feed rate.

Dehler et al. (2012) conducted two tests with borate treatments, using near-infrared sorting. The sorting sensors in that study were CCD cameras, which have opened new sorting possibilities in the mining industry. The difference between samples was based on the wavelength of the spectral response.

On the other hand, as liberation is a condition for a good separation, Ulsen (2013) has investigated mineral separability. CDW was crushed into fine aggregates and tested through density and magnetic separations. The separability studies were performed at laboratory scale, indicating that both density and magnetic separation were effective at reducing the content of cement paste and residual red ceramic particles because the cement paste and natural aggregates have a proper degree of liberation. The removal of cement paste and other porous phases is important for improving the quality of the recycled sand and enlarging the market for recycled aggregates. Liberation was also investigated by Lippiatt (2012) using microwaves, and overall test results show that concrete particles are severely damaged by exposure to microwaves. 
For Brazilian recycled concrete, Angulo (2010) has investigated how the classification of CDW (coarse aggregates), taking porosity into account, has affected the mechanical performance of concrete. The properties of recycled aggregate produced from mixed CDW (masonry and concrete) are highly variable, and this restricts the use of such aggregate in structural concrete production. The substitution of $100 \%$ coarse natural aggregate with the same volume of recycled aggregate tends to increase the amount of cement used for any given strength. The use of gravity separation by industrial density separators, such as jigs and heavy media, may lead to the production of high-quality recycled coarse aggregates from mixed CDW sources.

In urban and metropolitan areas, the building materials recycling industry has used stationary plants to process concrete and masonry demolition waste. Relatively pure, high-quality granules are produced with recycling requirements. Considering the environmental context, the aim of this paper is to make CDW more attractive with sorting systems. These systems can produce different flows with more homogeneous compositions and meet a specific reuse or recycling need. The processes detailed in this study are based on the use of gravity concentration and sensor-based sorting, which is known to be a less-polluting, energyefficient and cheaper alternative among mineral processing techniques. Therefore, increasing liberation is not a principal aim; the aim is only to obtain a precise classification using gravity concentration and automatic sorting.

\section{Mineral Processing Applied to CDW}

\subsection{Difficulty of liberation: use of mineral processing techniques with recycled concrete}

Several studies on recycled concrete have been published in recent years (Gomez-Soberon, 2002; Oikonomou, 2005; Akbarnezhad, 2010; Marie et al., 2012). Recycled concrete is produced by reducing the size of concrete debris through multiple crushing stages. According to Akbarnezhad (2010), depending on the size, the crushed concrete particles can present middling, which contains particles of natural aggregates mixed with mortars (Figure 1).

Figure 1 - Pictures of recycled aggregates $(6-10 \mathrm{~mm})$ taken from materials used by the Recybéton national project in France

After comminution, a mineral can be totally or partially liberated. The particles' liberation depends on their mineralogical origin, the quality of the concrete, the angularity of the original aggregates, the comminution process, size, and other factors. To increase liberation, a preparation circuit should be used to allow more intensive use of the recycled materials. More particles can be liberated with the beneficiation of recycled concrete material. In this sense, the use of innovative separation techniques in quarries, such as sensor-based sorting and/or gravity concentration, will increase the quality of the products generated, as well as the price for which they can be sold. These techniques, which are common in the mining industry, could ensure more efficient sorting in quarries.

Gravity concentration is defined as the process whereby particles of different sizes, shapes and densities are separated from each other by gravity or by centrifugal force. It is called gravity concentration because the separation is performed mainly based on density (specific gravity) (Sampaio, 2005). Gravity concentration processes have high mass throughput and low investment and operational costs. Moreover, there is no limit on the maximum particle size and the process can be used for particles with wide size ranges. Furthermore, reagents are not used, which contributes significantly to the low operational costs as well as to the low environmental impacts. 
Jigging is a separation process which consists of repeated expansion (dilatation) and contraction (compression) of a vertical bed of particles through a pulsating movement of water or air (Agricola, 1950; Lyman, 1992). The result is the stratification of the bed. The particles are deposited in layers of increasing density from top to bottom. Jigs were and still are widely used, mainly due to their costs. They have low operating costs, are robust, have high capacity, are easy to operate and can treat ores with a wide particle size range. They are also capable of working with large fluctuations in ore contents, feed rates and solids amounts. For this reason, they are widely used in the treatment of alluvial ores.

A Water-Only Cyclone (WOC) is a hydrocyclone in which density is the major separation property. The shape of the hydrocyclone was changed to improve the influence of particle density and to diminish the influence of particle size and shape (O'Brien, 1976) (Weyher, 1969). There are several different industry names for WOC, such as wide-angle cyclone, circulating-bed-concentrator (CBC), and autogenous hydrocyclone.

The use of optical sorting devices is increasing each year in the mining industry (Nienhauss et al., 2014) (Raulf et al., 2012). There are several reasons for the ever-increasing use of this type of sorting, such as the ability to automate the sorting process, the possibility of separation (quantity and accuracy), and the addition of economic value to the final products compared to the traditional separation process. In recycling, Angulo (2013) performed experiments on optical separation of bricks from CDW in Brazil. The main difficulty faced was the nonhomogenous Brazilian waste. Angulo identified significant variations in waste characteristics such as density and water absorption. The origin of these fluctuations, for example, the fluctuations in porosity, is due to red tiles, bricks and mortars. Density and water absorption are related to the porosity. The higher the water absorption, the higher the porosity. That is the main problem with mixed particles in aggregates; porosity has an important impact on the quality of concrete.

\subsection{New perspectives on sorting and liberation for recycling aggregates}

Despite techniques for sensor-based sorting and for gravity concentration processes, which are widely used in material recycling and in ore treatment (Sampaio, 2005; Wills, 2006), the choice of concentration equipment to be installed depends on the physical properties of the material to be beneficiated and the desired cut precision. Therefore, an extensive characterization before the mineral processing is indispensable. The main characteristics to be studied are porosity, water absorption and density distribution because these are associated with liberation. Many different separation or concentration techniques may be used, alone or in combination with others. Gravity concentration processes, for example, jigs and cyclones, have many positive characteristics, suggesting that they can be used to treat CDW.

\subsubsection{Current advanced process with CDW}

According to Kohler (1998), recycled materials produced from road demolition and CDW have mainly been re-used in low-quality applications, such as in road construction and in civil engineering projects. The re-use depends on environmental laws, which are different in each country, and on the responsibility of the producer. Specifically, the building materials recycling industry uses stationary plants to process concrete and masonry demolition waste. Relatively pure, high-quality granules should be produced to meet the recycling requirements. These requirements can be better met through systematic planning, adequate logistics, separate storage on the recycling site and the use of high-quality processing units.

Many studies show that RCA with different replacement rates provides quality concrete. The recent standard provides for the possibility of introducing recycled aggregates in structural concrete, with a limited substitution rate. In quarries, the material can be processed in stages: a first stage of sorting by many techniques, such as manual sorting and/or screening; and a 
second stage where sensor-based sorting and/or a gravity concentration is used. Additionally, the sand fraction has a relative importance in this context. If quarries produce a significant amount of fine particles, then recycling plants need to produce all sizes of fractions from recycled aggregates, including sands.

In modern recycling plants, ferrous scrap is pre-sieved and segregated using overhead magnetic separators. The use of picking belts enables separation of large disturbing substances before material with a particle size of $>45 \mathrm{~mm}$ is transformed into granules, mainly by impact crushers. After repeated segregation of separated ferrous scrap, there is a fractional sieving and separation of light substances using air classifiers. This technique allows for better production selected, similarly sized fraction granule mixtures. Products processed in this way are of high quality and can be used as recycling materials. This quality can be guaranteed by systematic quality monitoring and more intensive sampling and testing of the material characteristics (including environmental properties) than is the case for natural mineral substances (Figure 2). In France, this material is currently used on roads and terracing. It is rarely used on concrete structures. The aggregates for these applications are generally obtained from pre-screened sources (specific demolition sites which produce a large amount of non-contaminated concrete).

Figure 2 - Current advanced process in recycling platforms (Coelho A., et al., 2013, adapted)

\subsubsection{Process with supplementary sorting of the recycled concrete (first improved process)}

In an attempt to increase the recycling rate of concrete formulations, the use of high-quality recycled aggregates for off-site or on-site recycling is suggested (Figure 3). In this stage of recycling, gravity concentration by jigs and sensor-based sorting is used to separate different particles $(2 / 20 \mathrm{~mm})$, such as bricks, tiles, gypsum and glass, which were previously mixed together. The aim is to obtain high-quality particles and more liberated particles. These particles have similar colours and could not be separated by conventional optical sorting by colour. Impurities here are can represent approximately $14 \%$ of the total waste, according to Coelho (2013) and Ulsen (2013). Quality is evaluated using water absorption, density, MicroDeval or Los Angeles tests. Previous tests were carried out by Cazacliu (Cazacliu et al, 2013). These recycled aggregates, before concentrating, still contain a significant amount of adhered mortar. First, the jig will treat the coarser particles of recycled aggregates in two different density fractions. The fraction with density $>2.1 \mathrm{~g} / \mathrm{cm}^{3}$, which represents $90 \%$ of the aggregates, according to Sampaio (Sampaio, 2005), is sent to an optical sorter to generate a concentrate called Recycled Concrete Aggregate (RCA2). The impurities from sensor-based sorting, which represent at least $11 \%$ of the aggregate, based on jig efficiency, and the fraction with density $<2.1 \mathrm{~g} / \mathrm{cm}^{3}$ after the jig are called Light Recycled Aggregate of lower quality; both fractions are then sent to the next stage.

Figure 3 - New recycling platform scheme using mineral processing techniques with recycled concrete production. 


\subsubsection{Process with supplementary production of high-quality recycled concrete (second improved process)}

This process aims to further increase recycling rates, perhaps beyond $100 \%$ substitution of gravel. This process is developed for recycling or reusing the on-site materials to minimize the production of waste leaving the site. Additionally, the lower-density recycled sand may have applications in the manufacture of new cements or in public works applications with better binding properties, for example, their use as an additive (after re-grinding) during the production of concrete on site. In this study, we limit ourselves to studying how to sort recycled aggregates and the advantage of increasing the degree of substitution of aggregates at the site.

This stage of sorting receives Light Recycled Aggregate of low quality (density $<2.1 \mathrm{~g} / \mathrm{cm}^{3}$ ) and the impurities of jig and sensor-based sorting. All granules are crushed at size $<4 \mathrm{~mm}$ to liberate mortar that is adhered to the sand fraction $(0 / 4 \mathrm{~mm})$. A gyratory crusher is highly efficient at releasing aggregates, but another type of crusher can be used (PN Recybéton, 2011). Next, the WOC beneficiates the fines from lower-quality RCA into two fractions of different densities. The first fraction, with density $>2.1 \mathrm{~g} / \mathrm{cm}^{3}$, is sent to High-Quality Concrete Aggregate (RCA3). The second fraction from the WOC, with density $<2.1 \mathrm{~g} / \mathrm{cm}^{3}$, is sent to improve terracing (Figure 4).

This last stage is dedicated to increasing the quality of the products considered inferior, aiming at the production of top sands for high-quality concrete and earthworks. The advantages are a better concrete, more extended use of recycled material, less cement consumption, or maybe better road aggregates. The reduction in sorting compared to the current process can save costs. It also means a reduction in the gypsum still present in the mixture, due to the replacement of picking belts. The disadvantages are the costs that will be discussed later.

Figure 4 - Recycling production scheme for high-quality recycled concrete.

The efficiency of air jigs is lower than that of the same type of process using water (water jigs). Air jigs have a higher feeding rate as a function of the equipment size because the particles settle in air faster than in water (Sampaio, 2005). This makes the investment and operational costs lower.

The jig can be used primarily for the removal of a portion of the light particles (density $<2.1$ $\mathrm{g} / \mathrm{cm}^{3}$ ), as a rougher stage. The pre-concentrate (density $>2.1 \mathrm{~g} / \mathrm{cm}^{3}$ ) will be treated in the sensor-based sorting. In this way, many of the low-density particles will be removed in the jig and the final concentrate will be quite pure. A major disadvantage of using air jigs for the treatment of fine particles is their low efficiency. Particles below 2 or $3 \mathrm{~mm}$ are treated with very low efficiency in air jigs. For these sizes, wet processes are always recommended.

The choice of $2.1 \mathrm{~g} / \mathrm{cm}^{3}$ as the cut-off point for the aggregate density is based on two points: the normal concrete density, which is between $2.0 \mathrm{~g} / \mathrm{cm}^{3}$ and $2.6 \mathrm{~g} / \mathrm{cm}^{3}$, and lightweight concrete, which has a density lower than $2.0 \mathrm{~g} / \mathrm{cm}^{3}$, according to French Standard NF EN 206-1 (EN 206, 2011).

All the particles will be comminuted to under $4 \mathrm{~mm}$ (size of sands). In this last stage, a circuit of water-only cyclones was chosen, due to its versatility in gravity concentration as well as the size of the particles to be treated. Investment costs for a WOC circuit are very low. When they are used in series of 2 or 3 units, they present notably good cut efficiencies. 


\section{Method of Comparison}

\subsection{Relation between water absorption and the density of aggregates}

Water absorption and density values for fine and coarse aggregates of different types and sizes are shown in Figure 5 (adapted from Silva et al., 2004). The data represent 589 aggregates of different types, sizes and origins, sourced from 116 publications. There is a relationship between water absorption and density, which is mainly due to the porosity of the material. As the porosity increases, water absorption increases and density decreases. The polynomial regression curves have relatively high coefficients of determination $\left(\mathrm{R}^{2}=0.878\right)$, which means there is a very strong correlation between the two variables. Based on the data, Silva proposed an aggregate classification based partly on their composition but mostly on their physical properties. Additionally, the recycled aggregates for the proposed recycling plant, RCA1, RCA2 and RCA3, are indicated in Figure 5. It is relatively easy to obtain these products by changing the aggregate density cut-off point. The porosity or density can be changed, and other products could be produced according to quality needs (or market needs).

Figure 5 - Average polynomial curve for recycled aggregates and their classification based on water absorption and density (adapted from Silva, 2014), indicating new recycled products (RCA1, RCA2 and RCA3).

\subsection{Method to fix the substitution rate for a given concrete application}

A standard formula is proposed (for example, Aggregates $=1000 \mathrm{~kg}$, Sand $=900 \mathrm{~kg}$, Cement $=280 \mathrm{~kg}$ and Water $=180 \mathrm{~kg}$ ), without recycled aggregate, to allow an identical result for the RCA3 product (Figure 5). The substitution rate must be calculated on the entire aggregate (sand \& gravel). There is currently no clear method to predict differences in aggregate formulation when using similar aggregates with density and water absorption capacity variables (with different attached mortar contents). In a simplified way, an average level of absorption over the entire mixer was fixed (non-recycled gravel and recycled). This level of absorption helps to determine the gravel substitution rate in RCA1 and RCA2 products (Figure 5). The products are based on a typical concrete formulation and the density of a concrete mix can be calculated according to its proportions and densities:

$$
D=\frac{F A}{100} \times\left(\frac{s_{b u b t_{F R}} \times d_{F R A}+\left(100-s^{\prime} u b s t_{F R A}\right) \times d_{F N A}}{100}\right)+\frac{C A}{100} \times\left(\frac{s u b s t_{C R A} \times d_{C R A}+\left(100-s u b s t_{C R A}\right) \times d_{C N A}}{100}\right)
$$

where

D - Weighed density of concrete mixture;

FA - Percentage of fine aggregates used in the mixture;

CA - Percentage of coarse aggregates used in the mixture;

subst $_{\mathrm{FRA}}$ - Replacement level (\%) of fine natural aggregates with fine recycled aggregates;

subst $_{\text {CRA }}$ - Replacement level $(\%)$ of coarse natural aggregates with coarse recycled aggregates;

$\mathrm{d}_{\mathrm{FRA}}$ - density of fine recycled aggregates;

$\mathrm{d}_{\mathrm{FNA}}$ - density of fine natural aggregates;

$\mathrm{d}_{\mathrm{CRA}}$ - density of coarse recycled aggregates;

$\mathrm{d}_{\mathrm{CNA}}-$ density of coarse natural aggregates. 
According to this equation, the replacement of natural aggregates with recycled aggregates generates a decrease in density when all other parameters remain constant. Using the formulation for aggregates from RCA3 concrete, it is first necessary to determine the substitution rate for gravel alone. Then, if the rate is $100 \%$, it is possible to determine the rate of sand substitution.

To solve the above equation, it is necessary to know the water absorption of recycled gravel and sand. These values are determined by taking into account the average density of the aggregates. This density is determined based on different densities (average curves), with the separation density levels chosen using methods 2 and 3.

\subsection{Price of transportation and taxes}

It is important to determine the transportation costs of aggregates or recycled materials from construction and demolition. The price of transportation, $\mathrm{Pr}$, can be calculated as a function of distance, as follows:

$\operatorname{Pr}=\left(V C \times d+F C \times \frac{\left(\frac{d}{s}+t\right)}{10}\right) \times(1+m) / w$

where

$\operatorname{Pr}=$ price per tonnes $(€ /$ tons $)$

$\mathrm{VC}=$ variable costs $(€ /$ tons $)$

$\mathrm{FC}=$ fixed costs (€/day)

$\mathrm{d}=$ distance $(\mathrm{Km})$

$\mathrm{w}=$ weight per truck (tons) $=20$ tons fixed

$\mathrm{t}=$ time to charge and discharge $(\mathrm{h})$

$\mathrm{s}=\operatorname{speed}(\mathrm{Km} / \mathrm{h})$

$\mathrm{m}=$ profit margin

The costs of transport by truck can be related to the transport of virgin aggregates to construction sites or to the transport of CDW to recycling plants. The costs always have linearity with distance travelled (Figure 6). These results were obtained using a truck speed of $63 \mathrm{~km} / \mathrm{h}$, charge and discharge time of $2 \mathrm{~h}$, fixed costs of $156.01 € /$ day, variable costs of 0.43 $€ / \mathrm{km}$ and a profit margin of 0.33 .

\section{Figure 6 - Costs of aggregates transported by trucks in France}

Aggregate producers in France have posed some questions about transport costs, especially the indirect costs that are not clear in the current calculation. In fact, many other parameters should be incorporated in the costs table (Table 1), such as sanitary effects, overall pollution, environmental warming, noises, insecurity and infrastructure wear (DRE, Aquitaine 2004).

Table 1- Importance of indirect costs to transport modes (Source [2014]: http://www.unicem.fr/).

These indirect costs are associated with government taxes that could be higher based on the region or state. In the near future, a global vision of environmental impacts of aggregate transport by public and private parties will be necessary. 


\section{Results and Discussion}

\subsection{Optimal substitution rate}

The estimation of the water absorption of recycled aggregates from sorting plants, based on the aggregate replacement rate, is presented in Figure 7 . The average absorption and density of natural aggregates were considered to be $0.8 \%$ and $2650 \mathrm{~kg} / \mathrm{m}^{3}$, respectively. This figure clearly shows that the treatment greatly improves the quality of recycled aggregates, easily changing the water absorption (and densities) of the products.

According to the plant described (Figures 2, 3 and 4), the water absorption was $11.7 \%$ for RCA1, $7.0 \%$ for RCA2 and $3.6 \%$ for RCA3. Densities were $1900 \mathrm{~kg} / \mathrm{m}^{3}, 2085 \mathrm{~kg} / \mathrm{m}^{3}$ and $2210 \mathrm{~kg} / \mathrm{m}^{3}$, respectively.

Figure 7 - Estimation of water absorption of recycled aggregates RCA1, RCA2 and RCA3 obtained from treatment, based on the aggregate replacement rate.

In Figure 8, water absorption and densities are plotted together. The polynomial curve described by Silva (Silva, 2004) was added to assure that the values are not so distant from reality. Using this graphic it is possible to find mixtures having $0 \%$ to $100 \%$, natural or recycled aggregates respectively. In practice, the water absorption and density of desired products can be chosen. The percentages of aggregate mixtures can be achieved using a simple graphic method with a blending platform (see Figure 8). In this simple example, an aggregate with $4 \%$ water absorption and density of $2300 \mathrm{~kg} / \mathrm{m}^{3}$ (point $\mathrm{P}$ ) is produced. Many solutions are possible; however, it is not possible to reach a mixture of aggregates with $4 \%$ water absorption through only the use of RCA3 or natural aggregates. It is necessary to use RCA1 or RCA2, which is of lesser quality than RCA3 or natural aggregates. $\mathrm{P}^{\prime}$ is a mixture between RCA3 and natural aggregate at $65 \%$ and $35 \%$, respectively. The point $\mathrm{P}^{\prime}$ has approximately $2.6 \%$ water absorption and density of $2371 \mathrm{~kg} / \mathrm{m}^{3}$. This pre-mixture should be mixed again with RCA1 (85\% and 15\%, respectively) to obtain P. This is an approximate method that makes it possible to estimate aggregate proportions in recycled concretes.

Figure 8 - Range of recycled mixtures: graphic method used to obtain mixtures of recycled aggregates according to water absorption and densities.

\subsection{Increase in density and reduction in water absorption}

Figure 9 shows the possibility of increasing the quality of recycled aggregates with the use of a recycling plant. The probable gain in density or reduction in water absorption is linked with the percentages of replaced aggregates.

If $50 \%$ of RCA1 were replaced by RCA2, the expected density gain would be $4 \%$ (Figure 9a). On the other hand, if RCA1 were replaced by RCA3, the expected gain would be $8.4 \%$. The same situation is shown for a reduction in water absorption in Figure $9 \mathrm{~b}$.

The quality levels described in this analysis (i.e., levels of density and water absorption) can be assured by fine adjustment of gravity concentration equipment, mainly by changing the cut-off grade. The mass balance and the metallurgical balance should be set after any adjustments.

\section{a) Gain in density}


b) Reduction in water absorption

Figure 9 - The potential gain in density and reduction in water absorption, based on aggregate replacement rates.

Using the proposed method, the real possibility of quality improvement can be measured by the economic advantages obtained using the processing plant. In this context, the choice to improve or not improve sorting is related to the cost balance, including transport, distances and indirect costs.

\subsection{Acceptable cost limits for sorting equipment}

Studies to better understand the economic implications of the implementation and operation of a recycling plant have been conducted in several countries and have included sensitivity analyses. There is a high potential for profit in these endeavours, even considering the high initial investment requirements, which could indicate a clear alignment between the economic viability and environmental benefits resulting from these CDW recycling plants.

It is assumed that there is a site that can use recycled concrete, especially of RCA1 quality. It was decided to change RCA1 to another recycled aggregate (for example, RCA2) using the recycling platform. As RCA2 is of higher quality than RCA1, there is an increase in the total volume of recycled aggregate, $\Delta$, that can be used in the recycled concrete while maintaining the same quality. If RCA3 is used, there is another increase in the total volume of recycled concrete, $\varepsilon$, that can be used. The values of $\Delta$ and $\varepsilon$ were considered proportional to density gain, according to Figure 9a. The site studied is located $50 \mathrm{~km}$ from the quarry and $20 \mathrm{~km}$ from the discharge. For recycling in situ, a $2 \mathrm{~km}$ distance was considered for some displacements.

The transport of aggregates is a major factor in the costs. The rate of recycling or the distance to the quarry were analysed to find tendencies involving these costs. The possibility of reducing costs using recycling plants can be viewed in Figure 10a, based on the percentage of replaced aggregates, and in Figure 10b, based on the distance to the quarry.

For example, for a concrete that contains $50 \%$ recycled aggregates, such as RCA1, if $100 \%$ of this recycled aggregate is replaced by RCA2, the expected transport cost reduction will be approximately $3.8 \%$ (Figure 10a). On the other hand, if $100 \%$ of RCA1 is replaced by RCA3, the expected reduction will be approximately $8.1 \%$.

The cost reduction is exponential with the substitution rate of the recycled material. Furthermore, transport costs decrease when recycled material with superior quality is prioritized. A similar example for transportation distances to the quarry is shown in Figure 10b. In this case, the distance to the quarry has no importance for the reduction in transport costs. However, when recycled material with superior quality is prioritized, the transport costs are minimized. If the distance to the quarry is $50 \mathrm{~km}$, it is possible to reduce transport costs by at least $3.8 \%$ when RCA1 is replaced by RCA2 and up to $8.2 \%$ when RCA3 is used.

a) The cost reduction based on the aggregate substitution rate

b) The cost reduction based on distance to quarry

Figure 10 - The transport cost reduction based on the aggregate substitution rate and distance to quarry. 


\subsection{Relationship between quality of material and their operating costs, investments and profitability}

The authors performed simulations of projected investments and costs for construction waste processing plants, targeting different recycled products, with increasing levels of final quality. Projections signalled to the following preliminary conclusions:

- To obtain quality final of products is required an investment for RCA3 about $24 \%$ greater than RCA1 product, as well as the operating cost is about $27 \%$ higher;

- In terms of productions level, to produce a product with better quality, the recycle installation should have a minimum production capacity of $120 \mathrm{t} / \mathrm{h}(300 \mathrm{Kt} / \mathrm{year})$;

- In all cases must be counted with an entry charge at the plant a minimum price of $\$ 10.0 / \mathrm{t}$ of CDW.

\section{Conclusions and Perspectives}

The improvement of recycled concrete is the primary subject of this paper. The proposition is to increase the quality of recycled aggregates through supplementary use of widely used mineral processing techniques such as gravity concentration and sensor-based sorting, as alternatives to heat treatment.

A sorting plant is proposed. Fine and coarse aggregates are treated. During all stages of the sorting process, it is possible to adjust the quality (density and water absorption) of recycled aggregates. An approximate graphic method has been used to estimate proportions of mixed aggregates.

The main advantage of recycling plants is the superior quality of the materials. It is possible to increase the rate of concrete recycling and save costs. Though the environmental costs were not determined through a life cycle impact assessment in this study, $50 \mathrm{~km}$ was used as a maximal distance to transport CDW (see De Schepper, 2014).

The main disadvantage of recycling plants is the investment in sorting equipment. To obtain quality final of products is required an investment about $24 \%$ greater. Concerning productions level, the plants should have a minimum production capacity of $120 \mathrm{t} / \mathrm{h}$ (300 Kt/year). Their maintenance was not evaluated in this study. However, the gain in density and the reduction in water absorption were studied. In the study, replacing a lower-quality aggregate with another of medium quality, for instance replacing RCA1 with RCA2, leads to an expected density gain of approximately $4 \%$. On the other hand, if RCA1 is replaced by RCA3 (superior quality), the expected gain will reach $8.4 \%$. Consequently, there is a $34 \%$ reduction in water absorption.

Cost reductions for transport and discharge were analysed according to the aggregate replacement rate and distance to quarry. The cost reduction is exponential with the substitution rate of recycled materials. Furthermore, there is a decrease in transport costs if the quality of recycled aggregates increases. If the reduction in transport costs when the quality of recycled aggregates increases is taken into account, the distance between demolition site and quarry is not important. Transport costs are minimized when recycled aggregates with superior quality are manufactured. These costs can decrease by at least $3.8 \%$ when lower quality aggregates (RCA1) are replaced by higher quality aggregates (RCA2), and up to 8.2\% when the best recycled aggregates (RCA3) are used. 


\section{Acknowledgments}

The CAPES-COFECUB cooperation program between Brazil and France, the Federal University of Pampa (UNIPAMPA), the Federal University of Rio Grande do Sul State (UFRGS) and the French Institute of Science and Technology for Transport, Development and Networks (IFSTTAR) are acknowledged.

\section{Bibliography}

A. Akbarnezhad, K.C.G. Ong, M.H. Zhang, C.T. Tam, T.W.J. Foo., 2010. Microwaveassisted beneficiation of recycled concrete aggregates. Construction and Building Materials 25, 3469-3479.

Agricola, G., 1556. De Re Metallica, (Translated by H.C. Hoover e L.H. Hoover), Dover Publications (1950).

Ângulo, S.C., John, V.M., Carrijo, P. M., Figueiredo, A. D. and Chaves A. P., V., 2010. On the classification of mixed construction and demolition waste aggregate by porosity and its impact on the mechanical performance of concrete. Materials and Structures (2010) 43:519528. Doi 10.1617/s11527-009-9508-9.

Ângulo, S.C., John, V.M., Ulsen, C., Kahn, H., Mueller, A., 2013. Separação óptica do material cerâmico dos agregados mistos de resíduos de construção e demolição. Revista Ambiente construído, Porto Alegre, ISSN 1678-8621.

Cazacliu, B., Sampaio, C.H., Miltzarek, G., Petter, C., Le Guen, L., Paranhos, R., Huchet, F. And Kirchheim, A.P., 2013. The potential of using air jigging to sort recycled aggregates. Journal of Cleaner Production 66, 46-53.

Coelho, A. and de Brito, J., 2013. Economic viability analysis of a construction and demolition recycling plant in Portugal - part 1: location, materials, technology and economic analysis. Journal of Cleaner Production 39, 338-352.

Colas, S., Louis, H., Moreau, J. and Pasquier, J.L., 2013. La production de granulats par département. Datar - Observatoire des territoires, Ministère du développement durable, France.

Dehler, M., Robben, M., 2012. NIR versus Color Sorting of Industrial Minerals. Sensor Based Sorting Conference 2012, Aachen, Germany.

Ergün, L.Ş., Gülsoy, Ö.Y., Gülcan, E., 2012. Optical Sorting of Iron and Chromite Ores. Sensor Based Sorting Conference 2012, Aachen, Germany.

European Committee for Standardization, February 2011. Aggregates for concrete. Final Draft Fr EN 12.620.

European Committee for Standardization, September 19, 2011. Use of Aggregates in Concrete. TC104-SC1-TG19, Sixth Draft Text for EN 206.2011.

French Law $\mathrm{n}^{\circ}$ 2010-788, 2010. National engagement for environnemental (Grenelle de l'environnement). Ministère de l'écologie, du développement durable, des transports et du logement.

Gomez-Soberon, J.M.V, 2002. Porosity of recycled concrete with substitution of recycled concrete aggregate. An experimental study. Cement and concrete research 32, 1301- 1311.

Gülsoy, Ö.Y., Ergün, L.Ş., Gülcan, E., 2012. Optical Sorting of Low Rank Coals - a Subsidiary Study. Sensor Based Sorting Conference 2012, Aachen, Germany.

Kohler, G., and H. Kurkowski., Nov. 1998. Optimising the use of RCA. Sustainable construction: use of recycled concrete aggregate - proceedings of International Symposium. Department of Trade and Industry Conference Centre, London, UK, 11-12. http://trid.trb.org/view.aspx?id=709927.

Lippiatt, N. And Bourgeois, F., 2012. Investigation of microwave-assisted concrete recycling using single-particle testing. Minerals Engineering 31 (2012) 71-81. 
Lyman, G.J., 1992. Review of jigging principles and control, Coal Preparation, vol. 11, pp. 145-165.

Marie, I., Quiasrawi, H. Closed-loop recycling of recycled concrete aggregates, 2012. Journal of Cleaner Production 37, 243-248.

Miller, F.G., De Mull, T.J., Matoney, J.P., 1985. Centrifugal specific gravity separator, In: SME Mineral Processing Handbook (N.L. Weiss, ed.), SME, Littleton.

Muigai, R., M. G. Alexander, and P. Moyo., January 2013. "Cradle-to-Gate Environmental Impacts of the Concrete Industry in South Africa." Journal of the South African Institution of Civil Engineering 55, no. 2: 02-07.

Mulder, E., Tako P. R. J., and Lourens F., 2006. "Closed Cycle Construction: An Integrated Process for the Separation and Reuse of C\&D Waste." Waste Management, Wascon. 6th International Conference: Developments in the re-use of mineral waste, 27, no. 10 .

Nagataki S, Gokce A, Saeki T, Hisada M., 2004. Assessment of recycling process induced damage sensitivity of recycled concrete aggregates. Cem Concr Res; 34:965-71.

Nienhaus, K., Pretz, T., Wotruba, H., 2014. Sensor technologies: Impulses for the raw materials Industry. Shaker Verlag GmbH, Aachen. ISBN 978-3-8440-2563-7.

O'Brien, E.J., 1976. Water-only cyclones: their functions and performance, Coal Age, January, pp.110-114.

Oikonomou, N.D. Recycled concrete aggregates, 2005. Cement \& Concrete composites 27, 315-318.

PN Recybéton. May 2011. Complete Recycling of Concrete. Feasibility Report. PN Recybéton, France (in French).

Raoa, A., Jhab, K., Misraa, S., 2007. Use of aggregates from recycled construction and demolition waste in concrete. Resources, Conservation and Recycling 50, $71-81$.

Raulf, K., Pretz, T., Wotruba, H., 2012. Potential of Sensor Technologies in the Raw Materials of Industry. Sensor Based Sorting 2012, Aachen, Germany.

Sampaio, C.H, Tavares, L.M.M., 2005. Beneficiamento gravimétrico. Uma introdução aos processos de concentração mineral e reciclagem de materiais por densidade. Editora da Ufrgs.

Schepper, M., Van den Heede, P., Van Driessche, I. and De Belie, N. Life Cycle Assessment of Completely Recyclable Concrete. Materials, 2014, 7, 6010-6027.

Silva, R.V., Brito, J. and Dhir, R.K., 2014. Properties and composition of recycled aggregates from construction and demolition waste suitable for concrete production. Construction and Building Materials 65 (2014) 201-217.

Tam, V.W.I. and Tam, C.M., 2006. Evaluations of existing waste recycling methods: A Hong Kong study. Building and Environment 41 1649-1660.

Tromp, K.F., 1937. New methods of computing the washabilities of coals, Glükauf, vol. 37, pp. 125-156.

Ulsen, C., Kahn, H., Hawlitschek, G., Masini, E. et Angulo, S., 2013. Separability studies of construction and demolition waste recycled sand. Waste Management 33, 656-662.

Visman, J., 1962. Die Sortierung abriebempfindlicher Kohle im Hydrozyklon, proceedings, IV International Coal Preparation Congress, Harrogate, UK, pp.161-170.

Weyher, L.H.E., Lovell, H.L., 1969. Hydrocyclone washing of fine coal, Transactions AIME, vol. 244, pp. 191-203.

Wills, B.A., Napier Munn, T., 2006. Mineral Processing Technology. An Introduction to the Practical Aspects of Ore Treatment and Mineral. Elsevier Science \& Technology Books. 
Table 1- Importance of indirect costs on transport modes (Source: http://www.unicem.fr/).

\begin{tabular}{l|c|c|c|c}
\multirow{2}{*}{$\begin{array}{c}\text { Distance of } \\
\text { transport }\end{array}$} & \multicolumn{2}{|c|}{ Road } & Trail & River \\
\cline { 2 - 5 } & $50 \mathrm{~km}$ & $120 \mathrm{~km}$ & $120 \mathrm{~km}$ & - \\
\hline Directs costs & 4.0 to $4.5 € /$ ton & 7.2 to $8.4 € /$ ton & 6.6 to $7.8 € /$ ton & 6.8 to $20.0 € /$ ton \\
\hline Indirect costs & 1.3 to $5.8 € /$ ton & 3.0 to $14.0 € /$ ton & 0.7 to $2.6 € /$ ton & 0.5 to $3.0 € /$ ton
\end{tabular}




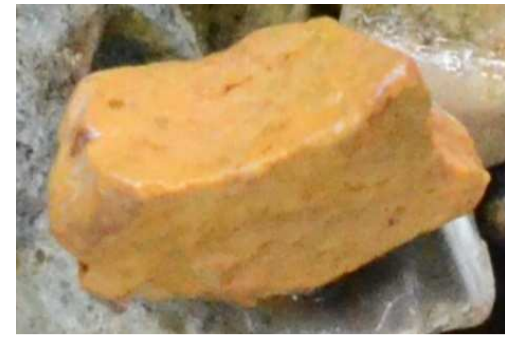

a) Natural aggregate

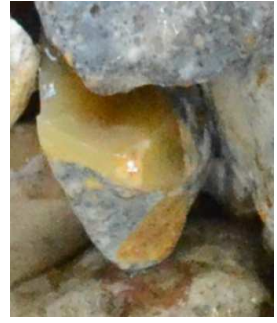

b) Middlings particles

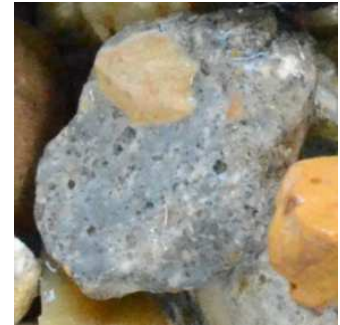

c) Mortar

Figure 1 - Pictures of recycled aggregates $(6-10 \mathrm{~mm})$ taken from materials used by Recybéton national project in France.

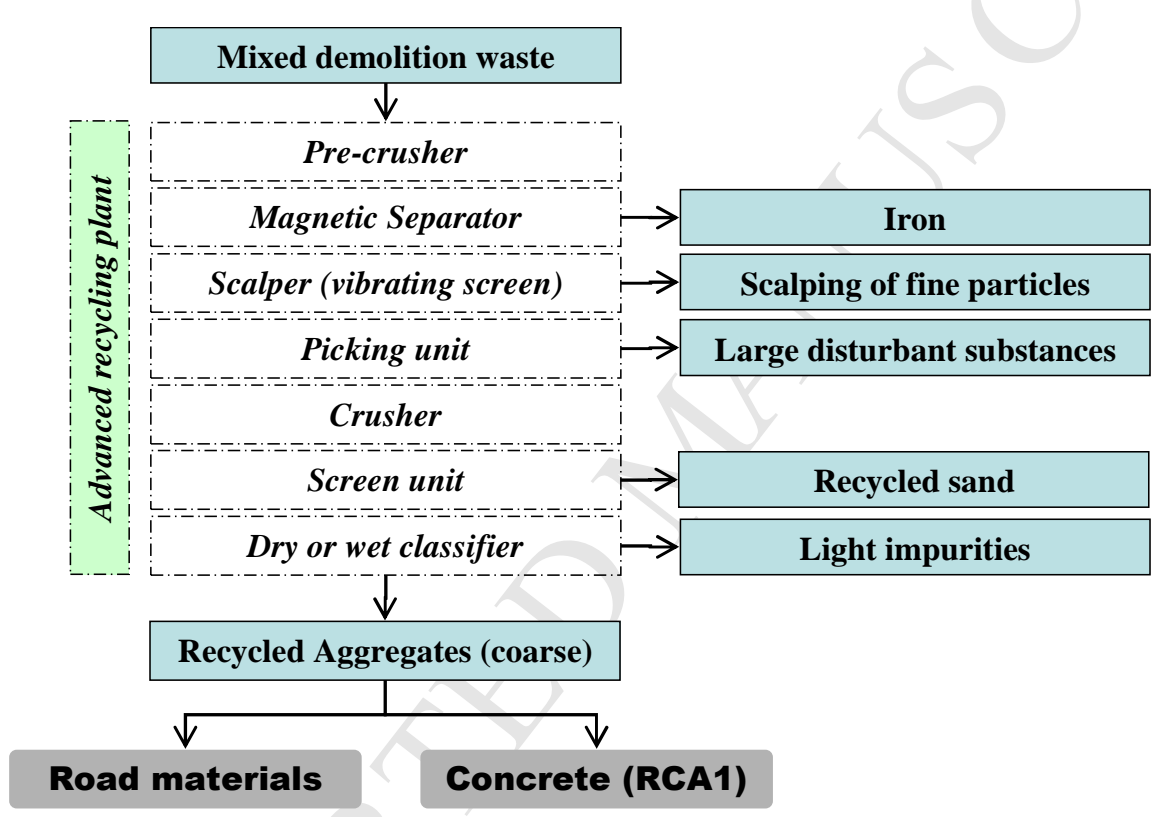

Figure 2 - Current advanced process in recycling platforms (Coelho A., et al., 2013, adapted) 


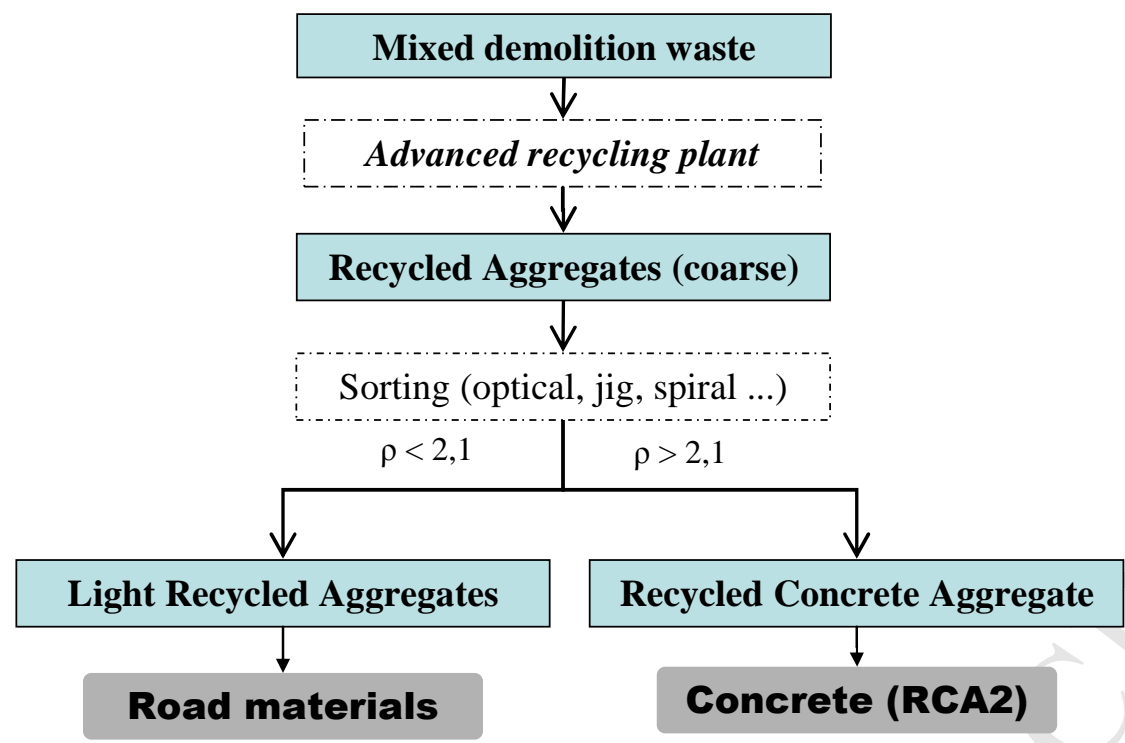

Figure 3 - New scheme of recycling platform using mineral process techniques with recycled concrete production. 


\section{Second improved process}

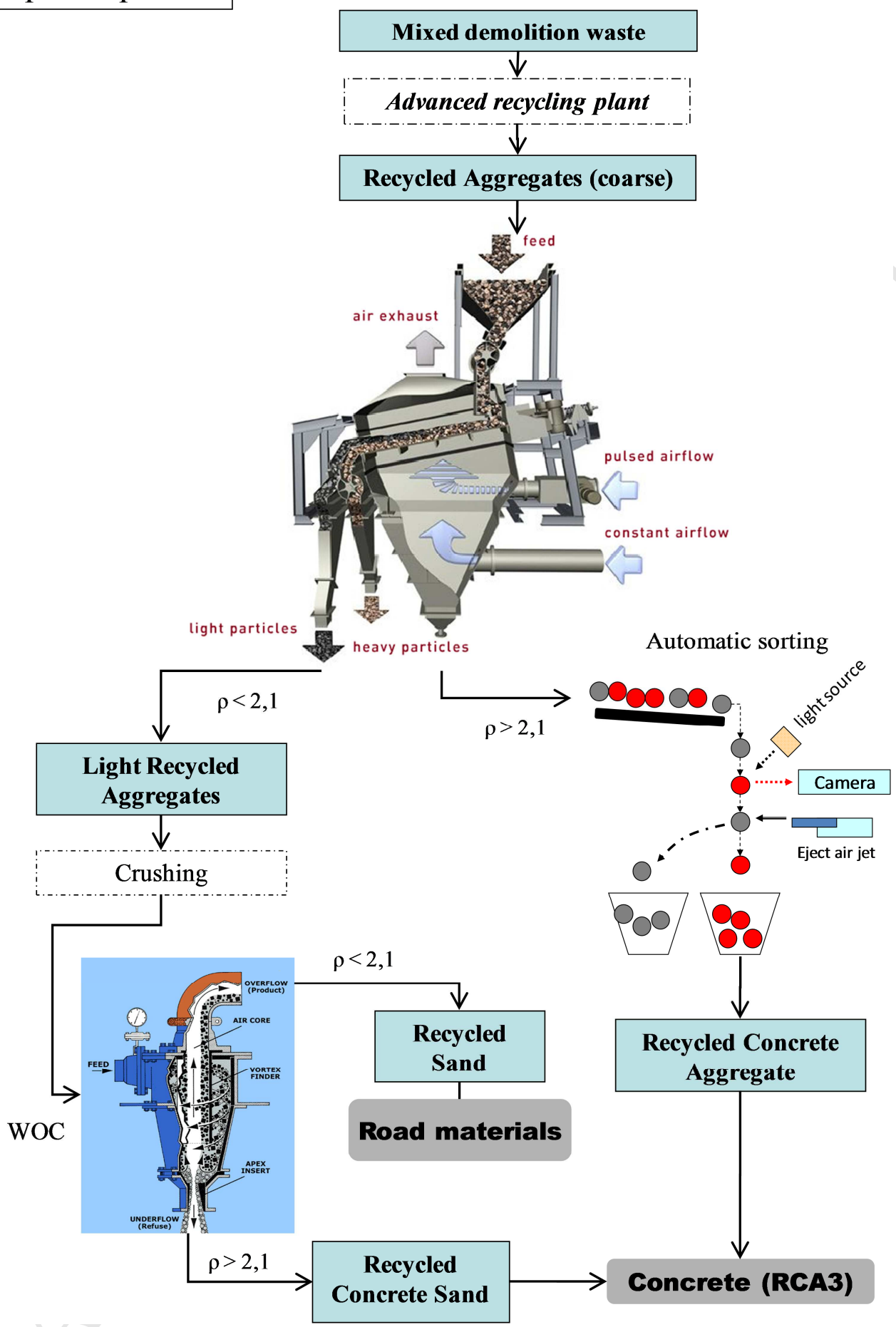

Figure 4 - Recycling production scheme for high-quality recycled concrete. 


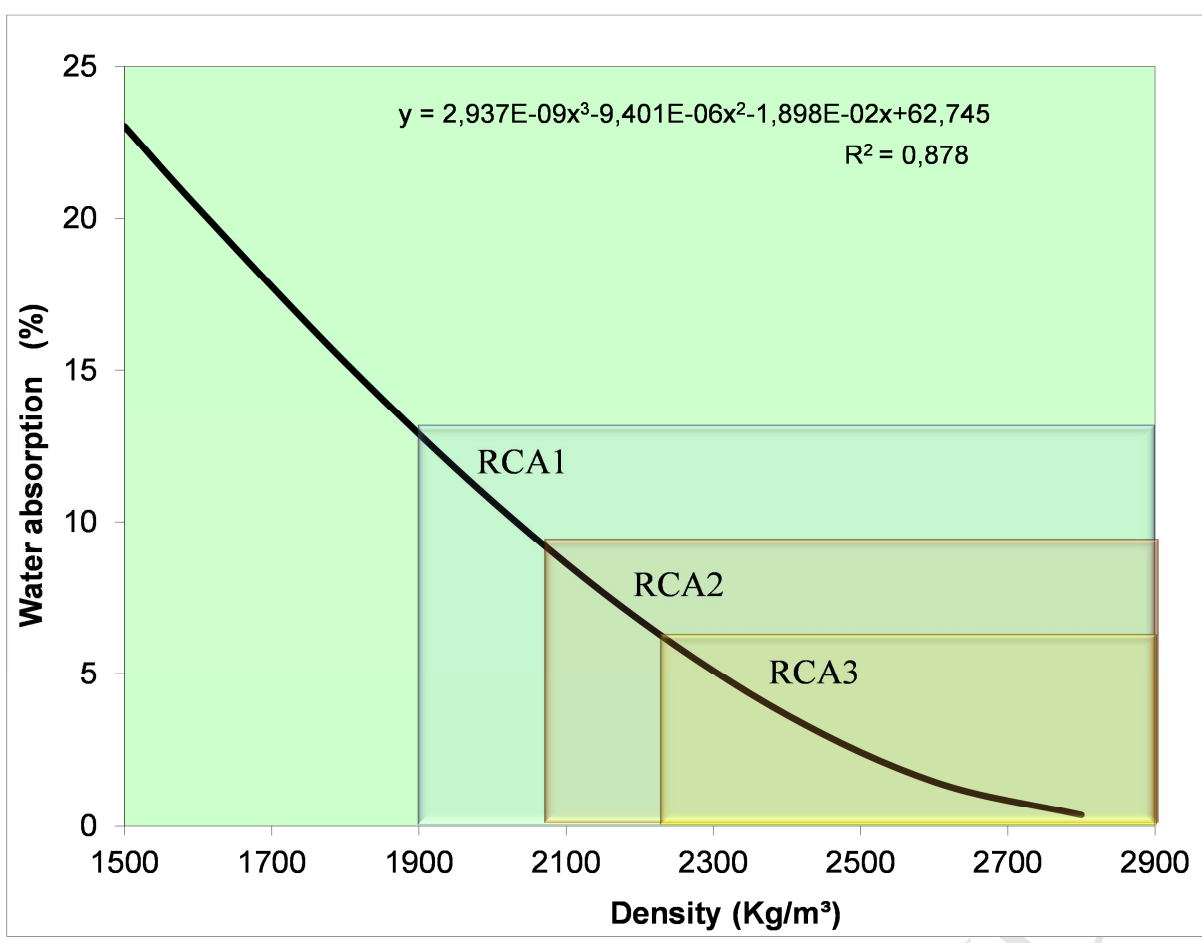

Figure 5-Average polynomial curve of recycled aggregates and their classification based on water absorption and density (adapted from Silva, 2014), indicating the new recycled products (RCA1, RCA2 and RCA3).

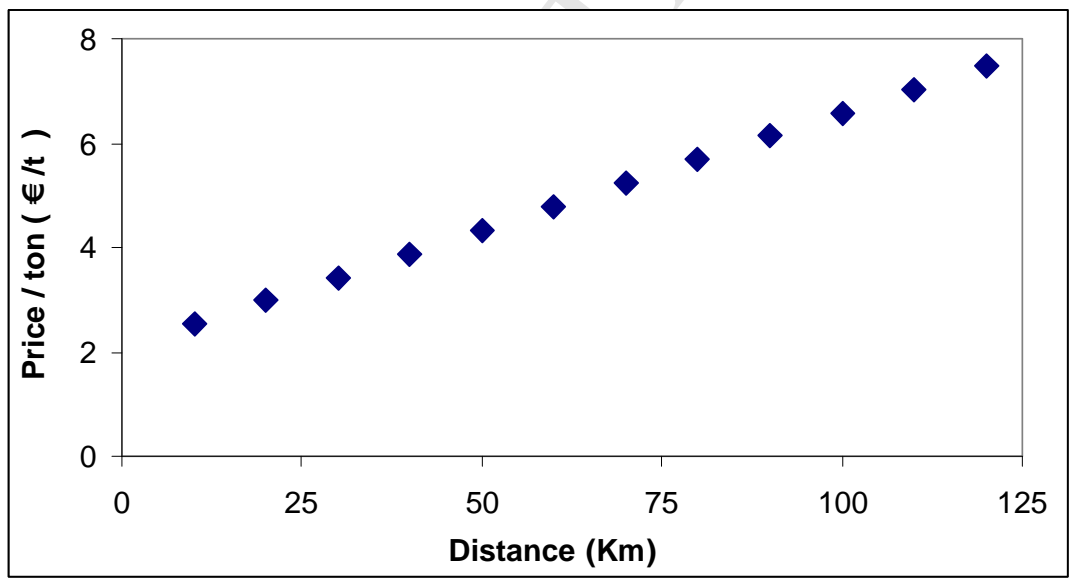

Figure 6 - Costs of aggregates transport by trucks in France 


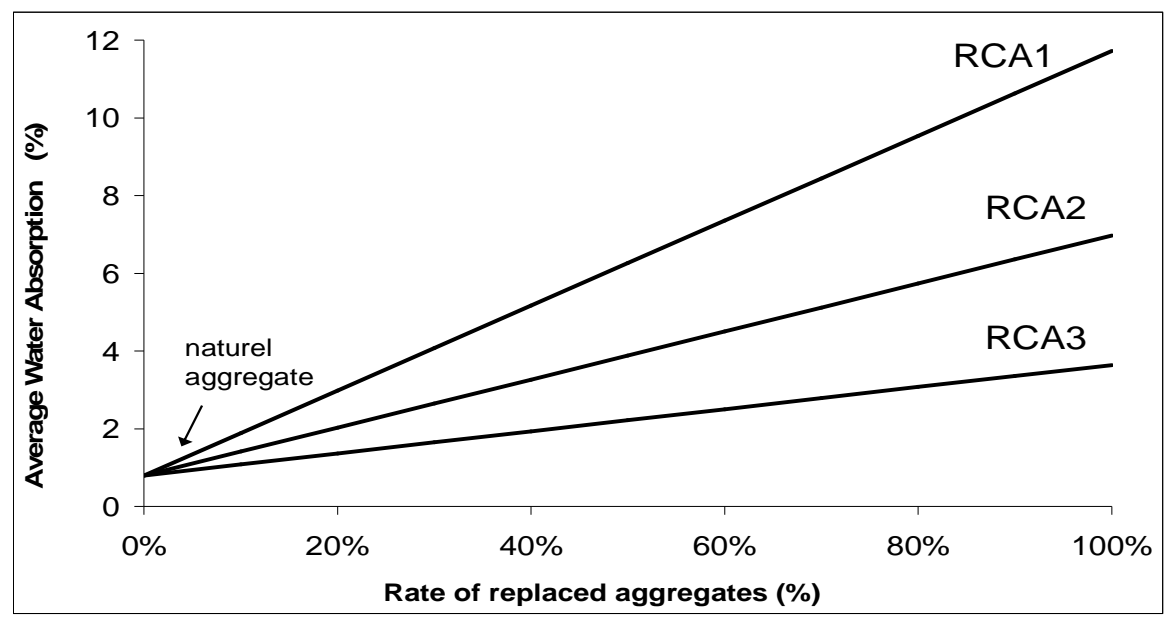

Figure 7 - Estimation of water absorption of recycled aggregates RCA1, RCA2 and RCA3 obtained from treatment, based on the aggregate replacement rate.

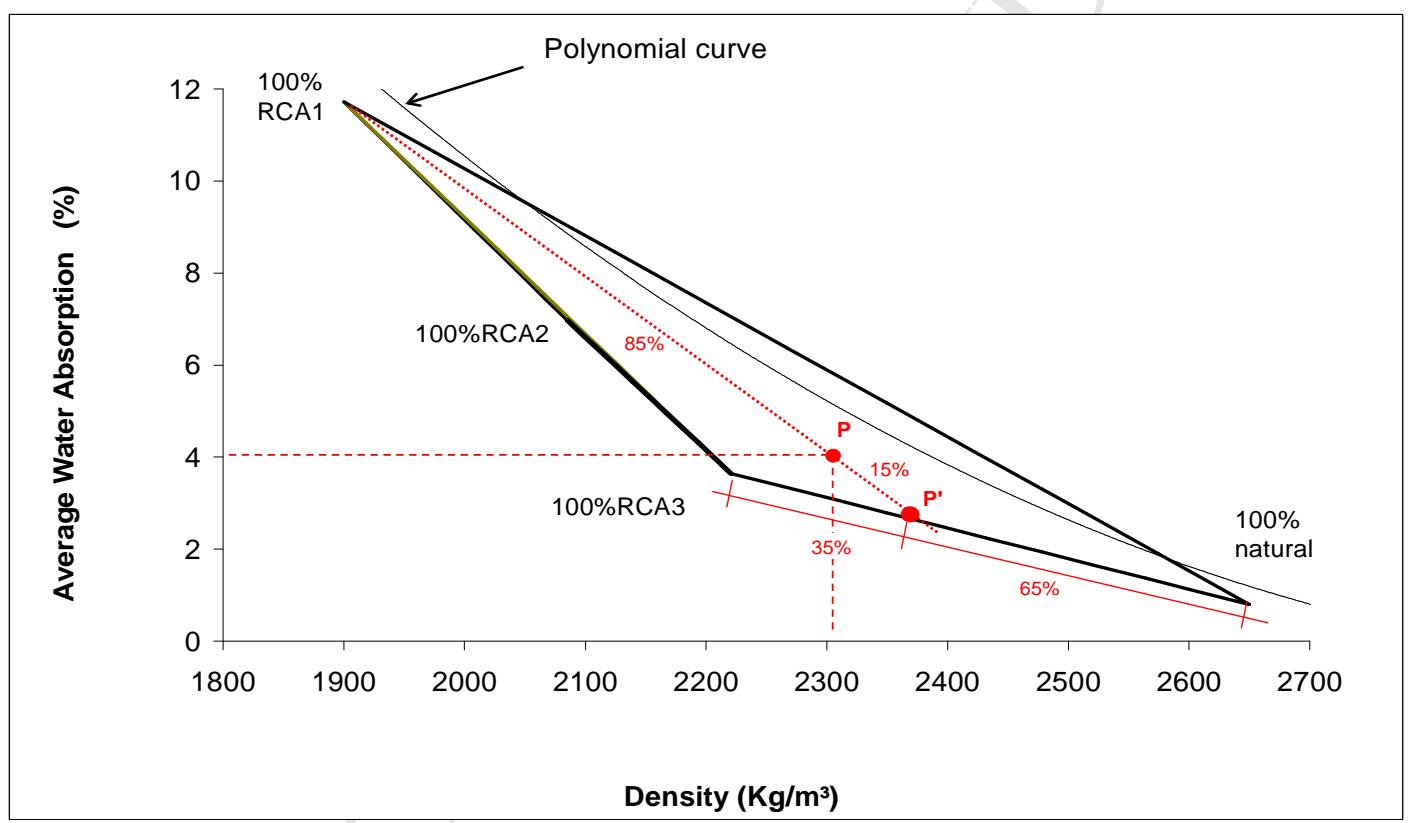

Figure 8 - Range of recycled mixtures: graphic method used to obtain mixtures of recycled aggregates according to water absorption and densities. 


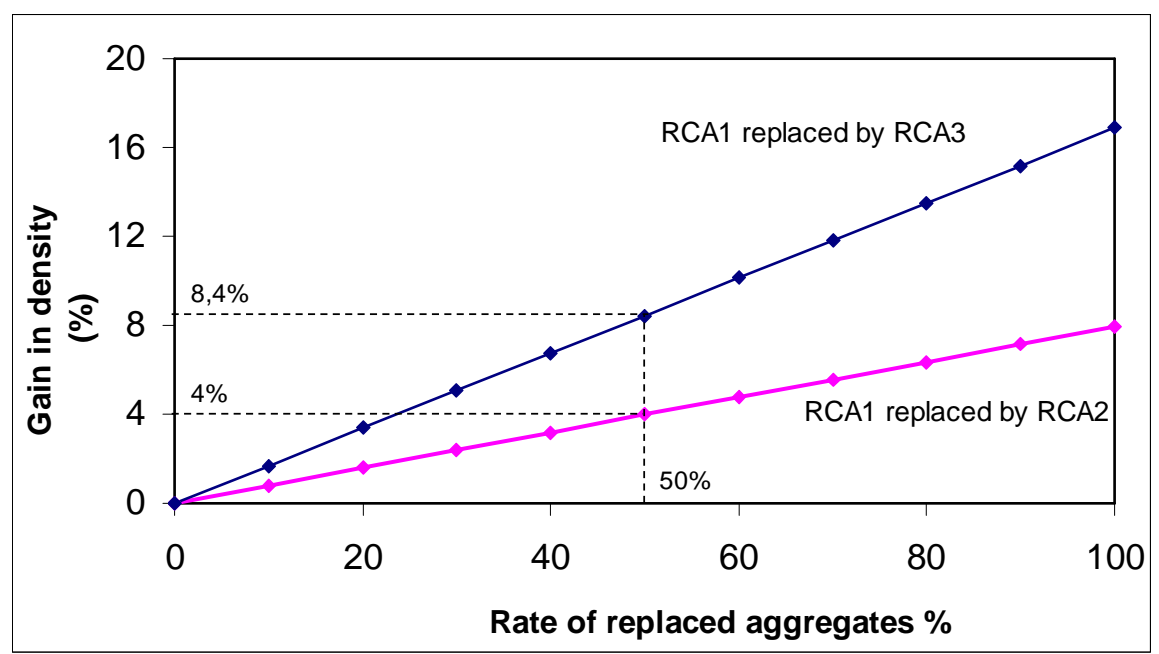

a) Gain in density

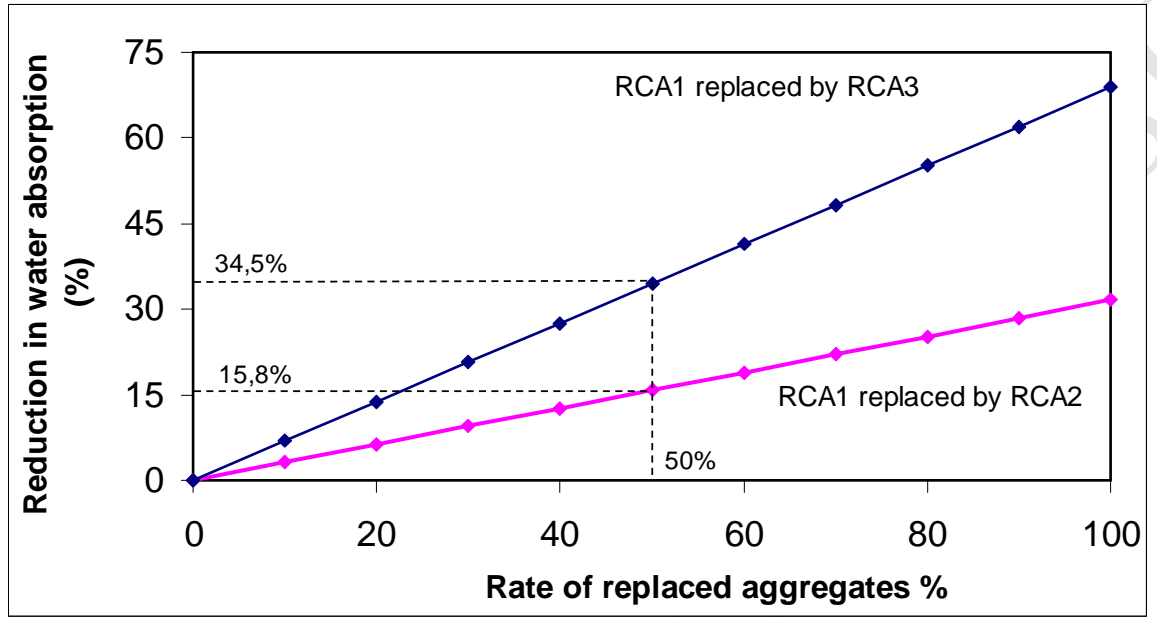

b) Reduction in water absorption

Figure 9 - The potential gain in density and the reduction in water absorption, based on aggregate replacement rates. 


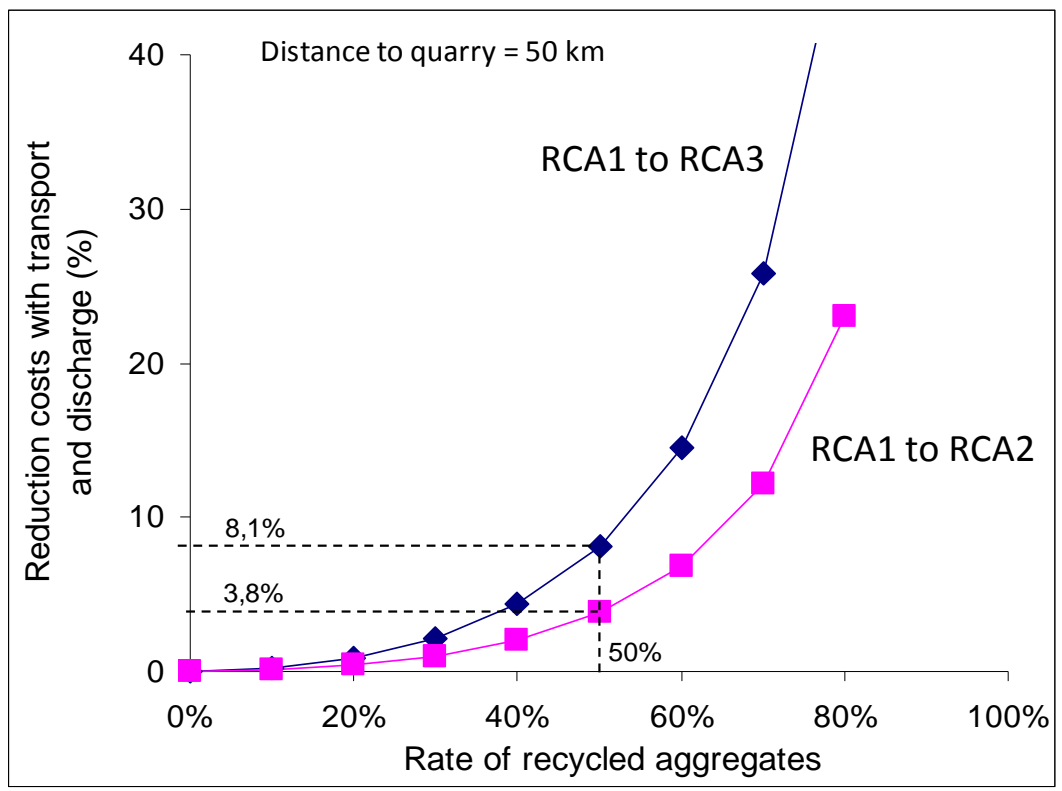

a) The cost reduction based on the aggregate substitution rate

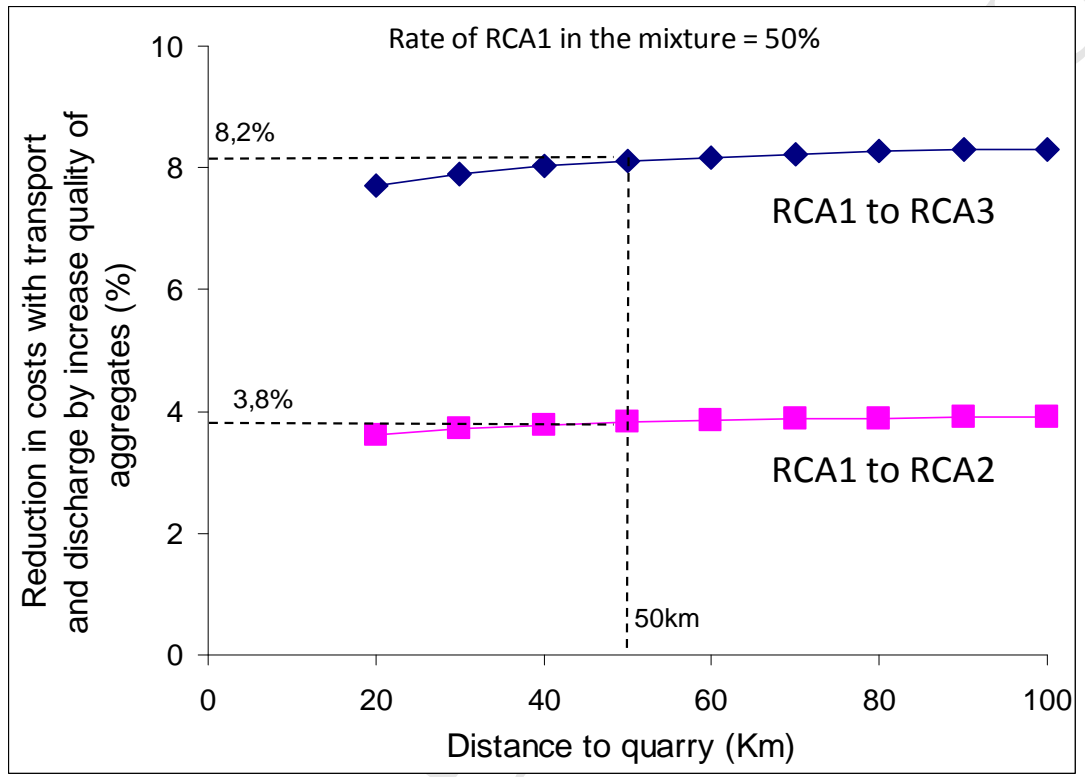

b) The cost reduction based on distance to quarry

Figure 10 - The transport cost reduction based on the aggregate substitution rate and distance to quarry. 